\title{
Evaluation of peak skeletal muscle perfusion in the lower extremities of athletes using arterial spin labeling
}

\author{
Mitchel R Stacy ${ }^{1 *}$, Christopher M Caracciolo ${ }^{1}$, Maolin Qiu², Albert J Sinusas ${ }^{1,2}$ \\ From 17th Annual SCMR Scientific Sessions \\ New Orleans, LA, USA. 16-19 January 2014
}

\section{Background}

Arterial spin labeling (ASL) magnetic resonance imaging (MRI) allows for evaluation of skeletal muscle perfusion and provides a non-invasive index of vascular function. Previous studies have investigated ASL responses during reactive hyperemia in healthy subjects and patients with peripheral vascular disease; however, ASL has not been applied for assessment of tissue perfusion in athletes. This study evaluated regional differences in peak tissue perfusion among calf muscle groups during reactive hyperemia in college football athletes and compared ASL responses to lower body strength and functional test results.

\section{Methods}

ASL MRI was performed on the mid-calf of 19 male athletes $(19.8 \pm 1.0 \mathrm{yrs})$ with a $3 \mathrm{~T}$ magnet to evaluate peak hyperemic tissue perfusion among individual muscle groups during reactive hyperemia induced by proximal cuff occlusion. Athletes were separated by position (larger linemen vs. smaller position players) for comparison purposes. Athletes' lower body strength and jumping ability were evaluated and compared to peak skeletal muscle perfusion responses.

\section{Results}

Linemen presented with higher body mass, body fat, and systolic blood pressure $(\mathrm{p}<0.05)$. Athletes did not significantly differ in maximal lower body strength; however, position players had greater vertical and broad jump performance ( $p<0.0001)$. In analysis of all athletes, the soleus muscle, a muscle with traditionally high capillary density, exhibited significantly higher peak perfusion during reactive hyperemia when compared to all other muscle groups $(\mathrm{p}<0.05)$. Additionally, peak perfusion in the 4 calf muscles of interest was significantly greater in position players when compared to linemen and was associated with greater jumping performance.

\section{Conclusions}

ASL MRI offers a non-invasive technique for quantifying regional differences in lower extremity tissue perfusion

Table 1

\begin{tabular}{|c|c|c|c|}
\hline \multicolumn{4}{|c|}{ Subject Characteristics and Functional Tests } \\
\hline & Linemen & Position Players & $P$-value \\
\hline Body Weight, kg & $118.9 \pm 6.8$ & $86.9 \pm 7.6$ & $<0.0001$ \\
\hline$\%$ Body Fat & $23.6 \pm 3.2$ & $10.2 \pm 2.1$ & $<0.0001$ \\
\hline Resting HR, bpm & $63.0 \pm 7.8$ & $57.5 \pm 9.5$ & 0.2 \\
\hline Systolic BP, mmHg & $137.6 \pm 11.9$ & $125.8 \pm 9.6$ & 0.03 \\
\hline Diastolic BP, mmHg & $82.9 \pm 8.3$ & $79.3 \pm 7.0$ & 0.3 \\
\hline Hang Clean, kg & $127.8 \pm 12.2$ & $117.1 \pm 10.9$ & 0.08 \\
\hline Back Squat, kg & $164.5 \pm 20.5$ & $155.1 \pm 17.7$ & 0.3 \\
\hline Sumo Dead Lift, kg & $179.0 \pm 24.7$ & $170.6 \pm 13.7$ & 0.4 \\
\hline Vertical Jump, m & $0.57 \pm 0.1$ & $0.72 \pm 0.1$ & $<0.0001$ \\
\hline Broad Jump, m & $2.4 \pm 0.1$ & $2.7 \pm 0.1$ & $<0.0001$ \\
\hline \multicolumn{4}{|c|}{ Peak Skeletal Muscle Perfusion (ml/100 g/min) } \\
\hline & Linemen & Position Players & P-value \\
\hline Soleus & $153.3 \pm 35.5$ & $210.4 \pm 45.7$ & $<0.001$ \\
\hline Gastrocnemius * & $71.2 \pm 13.1$ & $128.1 \pm 27.2$ & $<0.001$ \\
\hline Tibialis Anterior * & $63.2 \pm 12.7$ & $140.7 \pm 28.3$ & $<0.0001$ \\
\hline Fibularis Longus * & $82.9 \pm 20.7$ & $134.3 \pm 28.6$ & $<0.001$ \\
\hline
\end{tabular}

*, significantly different from soleus muscle $(p<0.05)$. 
and may relate to vascular density as well as functional performance. Assessment of peak skeletal muscle perfusion with ASL may help to evaluate and optimize exercise training for improved lower extremity function.

\section{Funding}

This work was supported in part by a medical research grant from the National Football League Charities Foundation and NIH grant T32 HL098069.

\section{Authors' details}

'Internal Medicine, Yale University School of Medicine, New Haven,

Connecticut, USA. 'Diagnostic Radiology, Yale University School of Medicine, New Haven, Connecticut, USA.

Published: 16 January 2014

doi:10.1186/1532-429X-16-S1-P164

Cite this article as: Stacy et al:: Evaluation of peak skeletal muscle perfusion in the lower extremities of athletes using arterial spin labeling. Journal of Cardiovascular Magnetic Resonance 2014 16(Suppl 1): P164.

Submit your next manuscript to BioMed Central and take full advantage of:

- Convenient online submission

- Thorough peer review

- No space constraints or color figure charges

- Immediate publication on acceptance

- Inclusion in PubMed, CAS, Scopus and Google Scholar

- Research which is freely available for redistribution

Submit your manuscript at www.biomedcentral.com/submit 